\title{
Creativity and fixation in the real world: a literature review of case study research
}

Nathan Crilly, University of Cambridge

Abstract: There are several prior case studies of design creativity which relate to design fixation. There is also a broader literature of qualitative research surrounding these cases, both within and beyond the design literature. However, these various texts are widely distributed, not well connected and seemingly not well known. This paper reviews the relevant literature, collecting many of these studies together for the first time. This allows the texts to be compared, their common themes to be identified and future work to be planned. More of such studies are necessary to increase the breadth and depth of accounts of creative design. This would permit connections and contrasts to be made and promote methodological diversity within research on inspiration and fixation.

Keywords: creative design, creativity, design fixation, product development, prototypes

"While it is easy to be wise after the event, the delay of almost a decade in arriving at this solution [for the design of the gas-turbine] could scarcely have occurred had a sufficiently abstract view of the problem been taken in the first case [...] Notice the role of established ideas $[\ldots]$ and the example of steam-turbine practice, in obscuring an important freedom of choice."

(French 1971/1998: pp. 202) 
How do designers develop new ideas? How do their ideas evolve and how do they move from one idea to the next? What is the role of prior design ideas in shaping new ones and what other factors influence idea development? For many years, these questions and others like them have motivated design researchers to study creativity. Recently, much of this attention has focussed on processes of inspiration and fixation, where example solutions or prior designs either stimulate or constrain a designer's imagination. It is not surprising that these issues have attracted the attention of researchers because creativity is the focus of much design education and design practice.

The questions we ask about design creativity are often - at least implicitly - questions about what actually happens in 'real world' design work, or what could happen or should happen in such work. However, there are very few detailed research accounts of how design ideas develop beyond the boundaries of laboratory studies or classroom projects. The majority of research in this area is experimental in nature where the need to control the variables of interest and collect data on idea generation restricts the contexts in which the design work can take place. On the other hand, case studies of professional design projects have seldom focussed on the details of how the design ideas developed from one stage of the project to the next, or how such developments were experienced by those involved. Where research accounts do refer to inspiration and fixation in the context of real-world projects, such descriptions are often rendered very abstract by the need to preserve the anonymity of the people, organisations and projects being discussed. As Linsey, Wessen, \& Ziemer (2016: p. 6) note, "Little work has followed concepts throughout the design process from the concept inception [...] to final production." This prevents researchers, whether employing experiments or other approaches, from having clear examples to refer to when describing their methods or their results, and it also limits theory development to a narrow range of methods. Consequently, there have been recent calls for case studies that detail the factors that contribute to the development of design ideas throughout a project, focussing on issues of creativity and fixation (Crilly \& Cardoso, 2017: §2.6, §2.8).

Motivation for conducting design creativity case studies might be strengthened by the observation that detailed research case studies of creative activities are common in other fields. For example, the creative work of Darwin, Einstein, Piaget and other famously inventive individuals is well described (e.g. see Wallace \& Gruber, 1989), as is the work of those whose achievements are less widely known (e.g. see Csikszentmihalyi, 1996; Hadamard, 1945; Shekerjian, 1991). These accounts typically focus on the specific advance that was made, who made it and how, all based on first-person accounts by the individuals who performed the work and archive research into how that work might be understood in the context of the preceding and following ideas in that field. Howard Gruber, in particular, has 
promoted the case study approach to understanding creativity. He describes how highly creative activities play out over very long time periods and involve individuals who have devoted their lives to the production of new ideas, knowledge or artefacts: creative work is part of a whole system of living (Gruber, 1988). Even though such case-based research methods are focussed on the specifics of individual people and projects, they can give rise to influential theories which are tested or elaborated through other research approaches (see Runco, 2003).

Taking the broader creativity literature as a point of inspiration suggests that conducting design case studies would be valuable for motivating, framing and developing further research. However, before conducting new case studies of design creativity and fixation, it is important to review those cases that have already been reported, even if they are spread through long time periods and across different disciplines, and even if it is only specific sections of such studies that are most relevant. Searching the literature reveals that there are actually several cases of interest, cases which describe either the context within which fixation occurs or episodes of fixation occurring. The remainder of the paper reviews these studies and the themes that emerge from them. We start with a discussion of the concept of fixation, especially how it is defined and studied in work adopting an experimental approach. There then follows a review of fixation in design projects, detailing the existing case studies and the surrounding literature, especially interview studies with professionals. One particular case study (the Hickman Case) is then elaborated in more detail because it is both especially valuable and seemingly unknown amongst those interested in fixation. The paper then ends with some conclusions calling for more case studies to be identified in the literature and more still to be newly conducted, and those cases (both old and new) to be integrated with ongoing research on design creativity and fixation.

\section{The concept of fixation}

Many research studies investigate design creativity by inducing design fixation through the presentation of example solutions that might either be inspiring or fixating. Jansson and Smith (1991) reported on the first laboratory-based experiment of this kind, where participants worked on design problems, including a car-mounted bicycle rack, a measuring cup for the blind or a disposable spill-proof coffee cup. Alongside the design briefs, some of the participants were also presented with pictures of existing solutions. Jansson and Smith identified the occurrence of fixation in their experiments when it was observed that the designers exposed to those pictures tended to repeat key features of the solutions that were represented. This behaviour persisted even when participants were instructed to avoid 
repeating particular features of those example solutions. Because these features were intentionally problematic (e.g. they contradicted the brief) this feature repetition was taken to be inadvertent and counterproductive.

To better understand design fixation, many research studies have been conducted, typically adopting the general experimental paradigm described by Jansson and Smith. These studies are sufficiently numerous that dedicated review papers have been published (Alipour, Faizi, Moradi, \& Akrami, 2017; Sio, Kotovsky, \& Cagan, 2015; Vasconcelos \& Crilly, 2016) in addition to the detailed reviews that are used to introduce empirical or theoretical work (for recent examples see Agogué, Poirel, Pineau, Houdé, \& Cassotti, 2014; Cheng, Mugge, \& Schoormans, 2014; Moreno, Blessing, Yang, Hernández, \& Wood, 2016; Viswanathan, Atilola, Esposito, \& Linsey, 2014; Youmans \& Arciszewski, 2014). These reviews all focus on experimental research into design fixation, and make little mention of the real-world design practices within which fixation occurs or examples of such occurrences. This is important to note because we might expect to find many differences between how design activities play out 'in the lab' and how they play out 'in the wild' (Ball \& Christensen, 2018; Cash, Hicks, \& Culley, 2013).

Observing that concepts of fixation have primarily been defined in the context of experimental research, it is important to consider how fixation might be identified in real world settings, especially in commercial design projects where some form of intellectual property claim might be made. For this it helps to remember that creativity and fixation are often seen as opposing concepts, either because fixation represents the absence, failure and restriction of creativity, or because creativity is required to resist, mitigate and avoid fixation. This is codified in legal discussions of invention, where a new design development might reveal the fixation of the preceding experts who failed to overcome their 'technical prejudice': "there is an inventive step if the prior art leads the person skilled in the art away from the procedure proposed by the invention." (European Patent Office. (n.d.)). Inventors are described as having challenged or gone against a prevailing 'technical prejudice' in the field (also known as a 'lion in the path') which had previously prevented other experts arriving at the same idea (for examples see Nicholson, 2007; Smyth, 2012). The inventors' creativity reveals the prevailing fixation; the prevailing fixation permits the inventors' creativity. Fixation can thus be a useful lens through which to view creativity, either because we want to see how designers detach from the prevailing ideas in the field or see how they detach from their own ideas. 


\section{Fixation in design projects}

Although laboratory experiments with student participants would seem to dominate research into design creativity and fixation, other approaches have also been applied. Where design researchers have engaged with the creative behaviour of experienced designers, this has often been in the form of protocol studies (or mixed method studies) undertaken in controlled settings. Such methods provide good opportunities for data capture but here the projects are still most often 'artificial', typically tackled over a few hours or less (e.g. see Ball, Evans, Dennis, \& Ormerod, 1997; Dorst \& Cross, 2001; Kim, Kim, Lee, \& Park, 2007; Lee \& Jirousek, 2015; Yilmaz, Daly, Seifert, \& Gonzalez, 2015; but for application of a longitudinal diary method see Ball, Evans, \& Dennis, 1994). Where more naturalistic observational studies engage with professional design activities, there is the chance to identify the attitudes and practices that are relevant to creative work on real projects. However, the commercial nature of these projects often means that the collected data includes a great deal of sensitive information. This either results in the details of the projects being obscured in the subsequent reports (e.g. see Shroyer, Lovins, Turns, Cardella, \& Atman, 2018; Wiltschnig, Christensen, \& Ball, 2013: p. 525) or in the reports being limited to the participants' reflections on their general experiences, detached from the detailed project examples to which they relate (e.g. see Busby \& Lloyd, 1999; Herring, Chang, Krantzler, \& Bailey, 2009). The same can be said for interview studies with professionals, such as Crilly's (2015) interviews with expert designers which focussed on their experiences of design fixation, their attitudes towards that phenomenon and the practices they adopt to address it. Real-world experiences of design fixation are being discussed in these interviews but not through accounts of the projects themselves.

The broader literature offers a few short passages describing fixation-like episodes in real design and development projects, including the Rolls-Royce jet engine example reported by French (1971/1998) and the Sony CD player example reported by Barker (1994). In each case, a preceding technology is described as the source of a mental block for the designers who are temporarily unable to imagine an alternative (also see Ferguson, 1992: pp. 15-22). Whilst these brief stories (and others like them) provide a valuable counterpoint to statistical reports and abstract reflections, they can also only offer a limited understanding of what occurred. The stories are reported in the form of anecdotes rather than research accounts and as such we know nothing about what data supports them, how that data was collected and whether the resulting stories would be recognised or accepted by those involved. There are also many other historical accounts of how products and technologies have developed, charting their changing features and configurations over long periods of time. However, 
these accounts are typically very far from offering any understanding of the ideas and experiences of those involved in the creative process (e.g. for examples, see Jewkes, Sawers, \& Stillerman, 1958; Eger \& Ehlhardt, 2018).

For first-person accounts of how and why design ideas develop through design projects, we must turn to research-based case studies, some of which are explicitly framed in terms of creativity: Roy's (1993) studies of projects by James Dyson (wheelbarrow, vacuum cleaner) and Mark Sanders (folding bicycle); Cross and Clayburn Cross's (1996) report on Gordon Murray's design practices (race cars, sports cars); Candy and Edmonds (1996) description of the design process of Mike Burrows (race bicycle); Cross's (2001) studies of projects by Kenneth Grange (camera, sewing machine, train); Dogan and Nersessian's (2010) research into James Stirling's design process (museum); Yilmaz and Seifert's (2011) study of an anonymous expert designer's work (bathroom solution for Alzheimer's patients); The Open University's (n.d) report on Andrew Ritchie's design work (folding bicycle). Fixation is not an explicit focus of any of these cases, but there are some relevant passages. For example, Dyson questions the value of expertise in the initial phases of a project so as to allow the questioning of established ideas, and Murray promotes the idea of designing things as though for the first time, disregarding assumptions and prior knowledge. These views are not connected to specific episodes in example projects, but are just reflections on their general experiences (for more such examples, see Crilly, 2015).

There are also at least three more studies (all reported in this journal) which deserve mention because they are close to, but not quite in line with, with our interests here. Lloyd and Snelders (2003) reconstruct a 'plausible account' of Philippe Starck's creative design process based on archival information. There are initial sketches and illustrations of potential sources of inspiration and other contextual information. However, with limited access to the designer's own account of the process (aside from prior interview comments in the press), the different versions of the story are more like a critical exploration of the centrality of the designer in determining the product's form (in this case a lemon juicer). Marion and Simpson (2009) describe the development of a new stapler product in a company's line up. This is a compelling case drawing on multiple forms of data, including CAD drawings and financial information. However, the product change is only incremental and the case is not described in terms of creativity. Shroyer, Lovins, Turns, Cardella and Atman (2018) report on a longitudinal study of an automotive design project based on a series of industry recordings made 'in the wild' (see Ball \& Christensen, 2018). By considering idea generation over different time periods, from minutes to months, Shroyer et al. identify the difficulty that the design team have in 'pinning down' exactly what the emerging ideas are, but there are few project details revealed, and no illustrations of a product or service being developed (again 
for reasons of confidentiality). Two much earlier case studies were also reported in the first volumes of Design Studies, Mueller's (1980) history of the development of circuit breakers and Shima's (1981) case history of a microprocessor. However, both of these cases are historical, managerial or industrial in nature, with no strong account of the thought processes of those involved.

Of the case studies reported in the design literature, it might be Cross's (2001) accounts of Grange's projects which provide the most detail of conceptual change. Each case involves Grange challenging assumptions for how things were before the project commenced: the camera film orientation was changed from landscape to portrait (because most of the images taken by users were of individual people); the sewing machine base was moved forward relative to the needle (because more room is required for fabric alignment prior to the stitch being made); the train buffers were removed from the design to improve the aerodynamics (because such a vehicle would not be used for shunting carriages in any case). With respect to fixation, this account of the train project is especially interesting because it describes interactions between the industrial designer (Grange) and the Chief Engineer. Grange's drive for improvements in efficiency and aesthetics leads to a fundamental assessment of the different functional requirements for the train and a recognition that legacy components could be discarded, components which had been compromising the design up to that point. There is acknowledgement from the engineer that this had previously been "overlooked": as Grange explains, "They'd never, ever made a complete train like that before - they made locomotives, and they made carriages [these separate components requiring buffers for shunting]" (p. 55). As Cross comments: "[Grange's] perseverance had led to the vital breakthrough. The buffers on this locomotive for a new, permanently-coupled train, could be dispensed with" (p. 55).

Neither the individual cases reported in the design literature nor the comparisons between them result in a generally applicable description of creative design work. However, there are still a number of recurring themes:

- personal experience often motivates the projects; the designers are not content with the status quo; they prefer to choose their own problems to work on; they function best when not driven by the requirements of other people;

- sudden illumination is not reported in all cases but hard work and persistence are; the designers become immersed in the problem for long periods during which there is an ever-increasing level of expertise in the problem and the proposed solution; 
- there is an essential idea or concept (sometimes captured in an early sketch); a single core idea is developed into a family of designs; there is creative work throughout the design process, including in detail design;

- iterative sketching, model making and testing are used to develop ideas (although some sketch a lot and some just make things); CAD is not prominent in the early ideation stages but is used during design refinement;

- ideas are sometimes developed easily (and might not work) but implementation and refinement are where the real challenges lie; possessing practical (making) skills and access to (workshop) resources is important for obtaining rapid and effective feedback on whether ideas will work;

- there is an element of chance in creative work; it is rare to employ formal creativity techniques, but there is often an analysis of existing products; the need for protectable intellectual property can influence the filtering of ideas;

- the designers sometimes maintain multiple channels of investigation at the same time; they might work in more than one domain; ideas are often transferred from one domain to another;

- the designers view the problem holistically, seeing the solution as part of a bigger 'system'; they view the problem in a new way, identifying the underlying principles from which a new solution can be derived;

- the designers often favour depth over breadth, examining and developing a small number of concepts (or a single concept) in detail rather than widely exploring a large space of possible problem-solutions.

Some of the themes outlined above can also be identified in design project accounts offered outside the design literature, accounts which are sometimes illustrated with depictions of the early prototypes and the designers' own reflections on the development of their ideas. These include stories that are recounted by the designers themselves: Alex Moulton's development of the 'Moulton' small-wheeled suspended bicycle (Moulton, 1979; also see Moulton, 1997); Ron Hickman's development of the 'Workmate' folding workbench (Hickman \& Roos, 1982; also see Landis, 1998); Trevor Baylis' development of the 'BayGen Freeplay' clockwork radio (Baylis, 1999: pp. 195-210); James Dyson's development of the 'dual cyclone' vacuum cleaner (Dyson, 2000: pp. 98-129). There are additionally accounts by those who were not directly involved, often focussed on specific interpretations of the projects: Rothwell and Gardiner's (1985) thorough examination of Christopher Cockerall's development of the hovercraft (examining the role of market forces and user involvement); Buijs' (1888) summary of Jim Hall's design of the 'Chaparall' race car series (emphasising the emergent 
and evolving means of controlling downforce); Dasgupta's (1994) historical-cognitive report on Maurice Wilkes' invention of the micro-computer (critically assessing whether creative thought is distinct from other forms of thought); Billington and Billington's (2013) accounts of the development of powered flight and microchips (examining the complex relationship between science and engineering); Filho, Tahim, Serafim and Moraes' (2017) reports on three cases of invention in South America (describing the challenges of innovation in two different countries).

Although not really reported as case studies, two other sets of accounts deserve mention here because they report on the creative work of high performing designers and because they informed some of other studies mentioned above. Lawson (1994) reports on wideranging interviews with ten leading architects with reference to actual projects and the sketches and models that represent idea development. In support of each interview, Lawson (1994) provides a good many drawings and models so that the reader can see some development within specific projects. However, the specific developments are not necessarily discussed by the designers and it is not always possible to understand the pressures on that development or the designers' process in reaching the eventual solution. Amongst numerous other themes, Lawson emphasises drawing as exploration, creativity under constraints, the importance of a central generating idea and the common practice of pursuing parallel lines of thought (also see related work by Heylighen \& Neuckermans, 2002).

In a similar style of study to Lawson's, Maccoby (1991) reports on interviews with eight peernominated engineers who are renowned for their inventive work, often giving a brief story of the process behind the particular projects that made them famous. The focus of the reports is on the engineers' backgrounds, their creative practices and their feelings about their own creativity. Again, some general themes emerge, overlapping with those described above: these people exhibit an intolerance for the worlds' imperfections, they are aware of and manage their working patterns, they see the problem as part of a bigger system and they exhibit persistence in the face of scepticism and criticism. Looking at each engineer in turn, specific topics relevant to design creativity and fixation emerge: for Jacob Rabinow there is a difference between addressing problems that have been given to you and those that you have discovered; for Carver Mead it is important to avoid discussing the problem initially because using the established language will just result in the same solutions; for Masaru Ibuka it is necessary to have a vision of the overall nature of the problem but also to be able to shift direction to reach the target; for John Pierce writing about the problem is an important process of understanding it coherently; for James Blinn tinkering is an effective means of learning; for Jun-Ichi Nishizawa the inventive process involves examining the 
nature and dimensions of the problem and then focussing on each detail with reading and experimentation; for Charles Townes switching specialties and being around those working on related topics are important stimuli; for John Cocke it is continuous work rather than flashes of insight that underpin his creative achievements. There is clearly a good overlap between these themes and those which are apparent in the other interviews and cases described above.

\section{The Hickman case}

From the above summary, it might seem that there are already many case studies of design creativity as it occurs in real world settings. However, these project accounts are all quite different in nature: some are high-level overviews whilst others refer to specific moments of the project; some include commentaries from the actual designers along with images of the prototypes they made whilst some are more much more distant or abstract; some focus solely on the designer's perspective whilst others consider the broader social and industrial context; some are connected to prior theories of design, creativity and invention whilst some purely focus on the projects being discussed. All the accounts are useful - especially collectively - in understanding what creative design looks like in real projects, but very few of them focus on the specific moments when the designers moved from one idea to another, on what motivated those moves or on what prevented those moves from being made earlier. This is likely because the data collection and data analysis conducted for these accounts were intended to emphasise other (and often broader) aspects of invention, design or innovation. Very few of the accounts can be re-read with respect to some new interests (such as representing an instance of fixation) because they are not reported in sufficient detail to permit that. It is only in Hickman's accounts of the development of the 'Workmate' that we find anything like the level of detail we might need to illustrate the challenges that designers experience in overcoming old ideas and in accepting new ones.

The fullest account of Hickman's project is achieved by combining two reports which each appear in sources that researchers interested in design and creativity might be unlikely to consult: Hickman's report to the Chartered Institute of Patent Attorneys (Hickman \& Roos, 1982) and a more recent interview reported in a book summarising the history and development of different types of workbench (Landis, 1998). Apparently, the only relevant work that cites either of those reports is by Roy (1993) who refers to "Hickman's idea of making the work surfaces of a workbench function as a vice" (p. 441) but does not expand on this further (the more extensive 1998 interview with Hickman was obviously not available at that time, and Roy was not focussing on fixation). However, Hickman's accounts provide a 
good foundation for describing how fixation and related phenomena might be experienced in real projects. As such, his design of the 'Workmate' is briefly summarised here, focussing on the details of how one significant design change was made (for the full story, including background, commercial developments and legal issues readers should consult the original 1982 and 1998 publications).

Both accounts explain that Hickman had a background in automotive design and production so when he found a personal need for a portable workbench he designed and made one himself. The first version was constructed by reusing two wooden beams that were readily available; he reports that had a larger single piece of timber been available instead then the invention that later resulted from the two-beam bench top configuration "would probably never have arisen" (1982: p. 428). To permit clamping of work pieces, a traditional woodworking vice was attached to one of the wooden beams and this vice remained present in subsequent prototypes. In addition to the primary clamping function which was satisfied by the traditional vice, Hickman was trying to determine the best way of clamping various tools between the two beams. Hickman reports suddenly noticing "for the first time" (1998 p. 214) the similarity between the two beams of the bench top and the two jaws of the traditional vice. He realised that the two beams could themselves act as a vice if one could be moved towards the other. The traditional vice could then be omitted altogether (with associated reductions in cost and weight) and the whole bench top would instead act as a kind of vice that the user would work on when they were not clamping work in it.

Despite the promise of the bench-top-as-vice concept, Hickman reports that he was initially resistant: there were various conventions for traditional vices and traditional benches that he was not yet prepared to give up. The idea was so radical that Hickman at first could not accept it himself and he didn't expect others to accept it either. He initially "abandoned" the bench-top-as-vice concept and his next prototype "maintained the early idea of two fixed beams" with a third movable beam positioned between them to offer clamping (1982: $p$. 430). Hickman "remained reluctant" to omit the traditional vice, was "worried" that convention ran strongly against what he was considering and that some of the consequences were "inherently ludicrous" (1998: p. 214). Eventually, however, he was "finally ready to omit the [traditional vice]" and adopt the bench-top-as-vice concept which then allowed a series of other changes that had previously been blocked by his adherence to precedent (1998: $p$. 214). The Workmate was subsequently manufactured and marketed by Black \& Decker with sales running in the tens of millions of units.

Hickman's accounts are especially detailed in two respects. First, we are provided with the sequence of thoughts and activities by which new ideas replaced the old ones and where 
the designer worked to identify, accept and implement those new ideas. Second, we are provided with an illustration of that process through the presentation of extant prototypes which are referenced at different points in the sequence: two beams with a traditional vice attached; two beams with a moving third beam in between them for clamping; two beams with one clamping against the other. None of the other cases reviewed here are quite so detailed in those respects and so it is really only Hickman's accounts that permits re-reading with a focus on new topics such as fixation.

\section{Conclusions}

There have been recent calls for design creativity case studies to be conducted and reported, cases which account for processes of inspiration and fixation, or more generally for how design ideas develop throughout a project. However, as this review has shown, there are already several directly relevant cases and a surrounding literature where the attitudes and practices of professional designers are reported. This literature would appear to be not well known, as cross-referencing between the cases is limited. What's more, reference to the cases in the experimental literature is practically non-existent, even when claims are being made about the real-world relevance of the phenomena of interest. This represents a missed opportunity as knowledge of case studies where fixation episodes are described in sufficient detail could inform theory development either directly, or through prompting the formation of hypotheses that could be tested by other research approaches. However, these existing case studies are quite few in number, were not conducted with a focus on fixation and not all were even focussed on creativity or inspiration. A larger, more detailed and more varied collection of cases would be required for design researchers to develop a thorough representation of creative design work. This would help to balance a topic that is predominantly studied with experimental methods, allowing the relevance and validity of current interpretations to be assessed and the planning of future work to be advanced.

\section{Acknowledgements}

The author would like to thank Roxana Moroşanu Firth for her comments on earlier drafts of this material and is also grateful to the editors and reviewers for their help in shaping this submission. This work was supported by the UK's Engineering and Physical Sciences Research Council (grant number EP/K008196/1). There is no data other than the cited material. 


\section{References}

Agogué, M., Poirel, N., Pineau, A., Houdé, O., \& Cassotti, M. (2014). The impact of age and training on creativity: A design-theory approach to study fixation effects. Thinking Skills and Creativity, 11, 33-41.

Alipour, L., Faizi, M., Moradi, A. M., \& Akrami, G. (2017). A review of design fixation: research directions and key factors. International Journal of Design Creativity and Innovation, 6(1-2), 1-14.

Ball, L. J., \& Christensen, B. T. (2018). Designing in the wild. Design Studies, 57, 1-8.

Ball, L. J., Evans, J. St. B. T., \& Dennis, I. (1994). Cognitive processes in engineering design: a longitudinal study. Ergonomics, 37(11), 1753-1786.

Ball, L. J., Evans, J. St. B.T., Dennis, I., \& Ormerod, T. C. (1997). Problem-solving Strategies and Expertise in Engineering Design. Thinking \& Reasoning, 3(4), 247-270.

Barker, J. A. (1994). Paradigms: The Business of Discovering the Future (Reprint edition). New York, NY: HarperBusiness.

Baylis, T. (1999). Clock This: My Life as an Inventor. London, UK: Headline Book Publishing.

Billington, D. P. \& Billington, D. P. Jr. (2013) The sources of modern engineering innovation. In 'Exceptional Creativity in Science and Technology: Individuals, Institutions and Innovations...' Andrew Robinson (Ed). pp 123-144. West Conshohocken, PN: Templeton Press.

Buijs, J. A. (1888) Innovation and Vision. In Creativity and Innovation: towards a European Network. Colemont, P., Grøholt, P., Rickards, T. \& Smeekes, H. (eds), pp. 57-62. Berlin Germany: Springer.

Busby, J. A., \& Lloyd, P. A. (1999). Influences on solution search processes in design organisations. Research in Engineering Design, 11(3), 158-171.

Candy, L., \& Edmonds, E. (1996). Creative design of the Lotus bicycle: implications for knowledge support systems research. Design Studies, 17(1), 71-90.

Cash, P. J., Hicks, B. J., \& Culley, S. J. (2013). A comparison of designer activity using core design situations in the laboratory and practice. Design Studies, 34(5), 575-611.

Cheng, P., Mugge, R., \& Schoormans, J. P. L. (2014). A new strategy to reduce design fixation: Presenting partial photographs to designers. Design Studies, 35(4), 374-391.

Crilly, N. (2015). Fixation and creativity in concept development: The attitudes and practices of expert designers. Design Studies, 38, 54-91.

Crilly, N., \& Cardoso, C. (2017). Where next for research on fixation, inspiration and creativity in design? Design Studies, 50, 1-38.

Cross, N. (2001). Achieving Pleasure from Purpose the Methods of Kenneth Grange, Product Designer. The Design Journal, 4(1), 48-58. 
Cross, N., \& Clayburn Cross, A. (1996). Winning by design: the methods of Gordon Murray, racing car designer. Design Studies, 17(1), 91-107.

Csikszentmihalyi, M. (1996). Creativity: flow and the psychology of discovery and invention. New York, NY: Harper Perennial.

Dasgupta, S. (1994). Creativity in Invention and Design: Computational and Cognitive Explorations of Technological Originality. Cambridge, UK: Cambridge University Press.

Dogan, F., \& Nersessian, N. J. (2010). Generic abstraction in design creativity: the case of Staatsgalerie by James Stirling. Design Studies, 31(3), 207-236.

Dorst, K., \& Cross, N. (2001). Creativity in the design process: co-evolution of problemsolution. Design Studies, 22(5), 425-437.

Dyson, J. (2000). Against the Odds: An Autobiography (2nd revised edition). London, UK: Texere Publishing.

Eger, A. O., \& Ehlhardt, H. (2018). On the Origin of Products: The Evolution of Product Innovation and Design. Cambridge, UK: Cambridge University Press.

European Patent Office. (n.d.). Overcoming a technical prejudice? (Guidelines for Examination: Part G, Chapter VII, Annex 4). Retrieved August 9, 2018, from https://www.epo.org/law-practice/legal-texts/html/guidelines/e/g viia $4 . h t m$

Filho, L. S., Tahim, E. F., Serafim, V. M., \& Moraes, C. B. de. (2017). From invention to Innovation-challenges and opportunities: a multiple case study of independent inventors in Brazil and Peru. RAI Revista de Administração e Inovação, 14(3), 180-187.

French, M. J. (1998). Engineering Design: The Conceptual Stage. London, UK: Heinemann Educational Books. Originally published in 1971.

Gruber, H. E. (1988) The evolving systems approach to creative work, Creativity Research Journal, 1(1), 27-51.

Hadamard, J. (1945). The Mathematician's Mind: The Psychology of Invention in the Mathematical Field. Princeton, NJ: Princeton University Press.

Herring, S. R., Chang, C.-C., Krantzler, J., \& Bailey, B. P. (2009). Getting inspired! Understanding how and why examples are used in creative design practice. Proceedings of the SIGCHI Conference on Human Factors in Computing Systems, 87-96.

Heylighen, A., \& Neuckermans, H. (2002). Are Architects Natural Case-Based Designers? Experts Speaking. The Design Journal, 5(2), 8-22.

Hickman, R. P. \& Roos, M. J. (1982) 'Workmate', CIPA Journal, July: 424-457. London, UK: Chartered Institute of Patent Attorneys.

Jansson, D. G., \& Smith, S. M. (1991). Design fixation. Design Studies, 12(1), 3-11.

Jewkes, J., Sawers, D., \& Stillerman, R. (1958). The sources of invention. London, UK: Macmillan. 
Kim, M. H., Kim, Y. S., Lee, H. S., \& Park, J. A. (2007). An underlying cognitive aspect of design creativity: Limited Commitment Mode control strategy. Design Studies, 28(6), 585604.

Landis, S. (1998). The Workbench Book: A Craftsman's Guide to Workbenches for Every Type of Woodworking. New Town, CT: The Taunton Press, Inc.

Lawson, B. (1994). Design in Mind. Oxford, UK: Butterworth-Heinemann.

Lee, J. S., \& Jirousek, C. (2015). The development of design ideas in the early apparel design process: a pilot study. International Journal of Fashion Design, Technology and Education, 8(2), 151-161.

Linsey, J. S., Wessen, R., \& Ziemer, J. (2016). Observations of a highly innovative group Directions for future research (pp. 1-9). Presented at The Fourth International Conference on Design Creativity, Atlanta, GA.

Lloyd, P., \& Snelders, D. (2003). What was Philippe Starck Thinking of? Design Studies, 24(3), 237-253.

Maccoby, M. (1991). The innovative mind at work. IEEE Spectrum, 28(12), 23-35.

Marion, T. J., \& Simpson, T. W. (2009). New product development practice application to an early-stage firm: the case of the PaperPro ${ }^{\circledR}$ StackMaster ${ }^{\mathrm{TM}}$. Design Studies, 30(5), 561-587.

Moulton, A. (1979). Innovation. Journal of the Royal Society of Arts, 128(5281), 31-44.

Moulton, A. (1997). A lifetimes experience of engineering innovations: success and failures. Sir Misha Black Memorial Medal Lecture Series. London, UK: Royal Academy of Engineering.

Moreno, D. P., Blessing, L. T., Yang, M. C., Hernández, A. A., \& Wood, K. L. (2016). Overcoming design fixation: Design by analogy studies and nonintuitive findings. Artificial Intelligence for Engineering Design, Analysis and Manufacturing, 30(02), 185-199.

Mueller, B. (1980). Case history of successful innovation: SF6 circuit-breakers, Design Studies: 1(5), 285-290.

Nicholson, C. (2007). TRIPS and paper tigers cause a stumble over inventive step. Journal of Intellectual Property Law \& Practice, 2(12), 788-790.

Rothwell, R., \& Gardiner, P. (1985). Invention, innovation, re-innovation and the role of the user: A case study of British hovercraft development. Technovation, 3(3), 167-186.

Roy, R. (1993). Case studies of creativity in innovative product development. Design Studies, 14(4), 423-443.

Runco, M. A. (2003). Where Will We Hang All of the Paintings? An Introduction to the Festschrift for Howard E. Gruber. Creativity Research Journal 15(1):1-2.

Shekerjian, D. (1991). Uncommon Genius: How Great Ideas are Born. New York, NY: Penguin Books.

Shima, M. (1981). Design case history: Z8000 microprocessor. Design Studies, 2(2), 97106. 
Shroyer, K., Lovins, T., Turns, J., Cardella, M. E., \& Atman, C. J. (2018). Timescales and ideaspace: An examination of idea generation in design practice. Design Studies, 57, 9-36.

Sio, U. N., Kotovsky, K., \& Cagan, J. (2015). Fixation or inspiration? A meta-analytic review of the role of examples on design processes. Design Studies, 39, 70-99.

Smyth, D. (2012). Lions in the path or paper tigers? Journal of Intellectual Property Law \& Practice, 7(7), 484-485.

The Open University. (n.d). OpenLearn - Topic 6: Design and innovation 3: The Brompton folding bicycle. Retrieved 6 August 2018: http://www.open.edu/openlearn/science-mathstechnology/engineering-and-technology/design-and-innovation/design/design/contentsection-0

Vasconcelos, L. A., \& Crilly, N. (2016). Inspiration and fixation: Questions, methods, findings, and challenges. Design Studies, 42, 1-32.

Viswanathan, V., Atilola, O., Esposito, N., \& Linsey, J. (2014). A study on the role of physical models in the mitigation of design fixation. Journal of Engineering Design, 25(1-3), 25-43.

Wallace, D. B., \& Gruber, H. E. (1989). Creative people at work: twelve cognitive case studies. Oxford, UK: Oxford University Press.

Wiltschnig, S., Christensen, B. T., \& Ball, L. J. (2013). Collaborative problem-solution coevolution in creative design. Design Studies, 34(5), 515-542.

Yilmaz, S., Daly, S., Seifert, C., \& Gonzalez, R. (2015). How do designers generate new ideas? Design heuristics across two disciplines. Design Science, 1, E4.

Yilmaz, S., \& Seifert, C. M. (2011). Creativity through design heuristics: A case study of expert product design. Design Studies, 32(4), 384-415.

Youmans, R. J., \& Arciszewski, T. (2014). Design fixation: Classifications and modern methods of prevention. Al EDAM, 28(02), 129-137. 